\title{
SOBRE O CUIDADO DE OUTROS EM CONTEXTOS DE POBREZA, USO DE DROGAS E MARGINALIZAÇÃO*
}

María Epele

O presente trabalho é sobre o Cuidado. A proposta consiste na abordagem de cuidado como um conjunto de tecnologias corporais, vinculares, subjetivas e políticas. Especificamente há anos venho documentando a problemática nos bairros marginalizados da área metropolitana de Buenos Aires: quais são os modos "adequados" de cuidar de outros, não só em relação aos "novos problemas", mas também aos que, como dizem os próprios atores sociais, "não se sabe como cuidar", "não se deixam cuidar", ou aos que não se ajustam ao conjunto disponível de sujeitos e práticas das tradições locais de cuidado. "Outros" e "problemas" sobre os quais, além disso, há o registro de uma longa história de intervenção por parte de diversas instituições (políticas, justiça, saúde, policiais, religiosas, não governamentais etc.).

Com a generalização do consumo de PB/Paco (PB: Pasta Base de Cocaína, também chamada de Paco) nos setores populares durante a crise de 2001-2002, extremaram-se e evidenciaram-se como "novos" certos problemas sociais, vinculares e de saúde que tinham um complicado e longo processo de produção (Sedronar 2007; Touzé 2006; Epele 2011). Entre esses problemas, o rápido emagrecimento dos jovens consumidores intensivos de PB/Paco surgiu como algo inédito nas já complicadas topologias corporais produzidas pelas mutações das relações entre pobreza, magreza, desnutrição, obesidade e fome nos setores populares durante as últimas décadas (Aguirre 2004; Ortale 2005; Miguez 2007).

Através da avaliação das particularidades de algumas práticas, de saberes e estratégias com que os familiares de usuários/as de drogas - e residentes em geral - respondem diante do rápido emagrecimento desses jovens, o objetivo do presente trabalho é expor a problemática das práticas e dos processos envolvidos e categorizados como de Cuidado para outros especificamente, para usuários/as de drogas em contextos sociais marginalizados da área metropolitana de Buenos Aires. Neste caso, esses "outros" 
são sujeitos que realizam ações autorreferenciais que envolvem graus variáveis de prazer e de dano e que, por sua vez, são socialmente punidas e criminalizadas.

Diversos estudos em ciências sociais e antropologia assinalaram os modos com que o cuidado tem sido desvalorizado nas sociedades ocidentais por estar associado às emoções, à intimidade e aos setores sociais subordinados: mulheres, pobres, minorias étnicas etc. (Held 2006; Tronto 1994). Ao questionar esta naturalização, o cuidado é entendido como um complicado processo que consome energia, tempo, recursos financeiros, no qual intervêm saberes, redes sociais, tecnologias, tarefas e corpos, e que deixa lugar à fragilidade, à incerteza e à incorporação da experiência própria e dos outros em seu desenvolvimento (Mol 2007; Kleinman \& Hanna 2008).

Partindo dessas perspectivas e integrando os desenvolvimentos de Foucault (1989), no presente trabalho analiso as práticas e os saberes categorizados como cuidado pelos próprios atores sociais em termos de tecnologias. Desta perspectiva, o cuidado em sua diversidade e pluralidade pode ser considerado em termos de produção, quer dizer, como um conjunto de técnicas e táticas que se transformam no tempo, integrando tanto as redes sociais e as lógicas de poder quanto os processos de subjetivação, incorporando, ajustando e desenvolvendo saberes e práticas de diferentes procedências (Foucault 2006; Pita 2010). Além disso, e seguindo os desenvolvimentos de Ulloa (1995), algumas das técnicas participam de certos "encerramentos trágicos" que há décadas foram se constituindo em relação à problemática do consumo de drogas e através dos quais os processos macrossociais se traduzem em - e promovem - dinâmicas de maus-tratos e/ou descaso nos vínculos entre as instituições e as populações marginalizadas (Aureano 1999; Altschul \& Taber 2005). Diferentemente da racionalidade técnica da biomedicina, os saberes e as práticas referidos ao cuidado são produzidos social e historicamente a respeito das áreas específicas de experiência (Kleinman 2009). Além disso, essas práticas integram na mesma trama da vida cotidiana experiências — crônicas - na maneira de tratar diversas políticas e instituições e incluem diversos modelos de subjetividade e de cidadania.

Finalmente, promover o questionamento sobre o cuidado, no que diz respeito ao uso problemático de drogas, uma das áreas mais complexas da vida cotidiana dos setores populares, envolve a produção de uma nova visão baseada na pesquisa e no debate sobre problemas de longa data, com genealogias complexas e futuros incertos. Também abre a possibilidade de produzir novos e múltiplos canais, institucionais e informais, geradores de novos laços sociais e subjetividades. 


\section{Sobre o cuidado}

Nas últimas décadas, o cuidado em geral e a saúde em particular têm se convertido em um problema a ser pesquisado tanto na saúde pública quanto nas ciências sociais e na antropologia. Esses desenvolvimentos puseram em evidência um domínio de atividades, saberes e lógicas que tinham ficado invisíveis e marginalizados nas sociedades ocidentais (Kleinman 2009; Ayres 2000). Como certos autores assinalaram, esta marginalização se deve ao fato de que a indagação sobre o cuidado comove os pressupostos epistemológicos, políticos e morais envolvidos na produção de bem-estar, saúde e cidadania em nossas sociedades (Mol 2007; Tronto 1994).

Em primeiro lugar, falar em cuidado significa questionar os dualismos que suportaram a racionalidade iluminista instrumental e, portanto, a ideologia do sujeito liberal. Além dos dualismos clássicos que atravessam a epistemologia ocidental (corpo/mente, natureza/cultura, indivíduo/sociedade etc.), a noção de cuidado interpela diretamente as oposições e as tensões entre autonomia/dependência, controle/atenção, saber/prática, fatos e valores (Mol 2008). Em segundo lugar, as atividades e as práticas de cuidado e aqueles que as realizam são marginalizados, devido à associação que esta noção tem com o emocional, o particular, o lar, as mulheres e as necessidades. Isto mostra que a maioria das pessoas que realizam as atividades, na geografia social, é principalmente de classe baixa, mulheres, membros de minorias migrantes ou étnicas (Kleinman \& Hanna 2008). Através de quem cuida de quem, ficam então em evidência os modelos de subordinação social. Enquanto as classes privilegiadas contam com recursos para pagar outros que deles cuidem, os setores populares deixam de cuidar dos seus para trabalharem no cuidado dos membros de outras classes sociais (Tronto 1994).

Essas perspectivas, por sua vez, têm uma relevância central para a pesquisa socioantropológica sobre saúde-doença. Seguindo Mol (2008), focalizar a análise do cuidado em geral e da saúde em particular envolve a tarefa de questionar o monopólio da "escolha" que progressivamente colonizou como ideal exclusivo os cenários dos tratamentos. Enquanto a escolha é uma ação racional que hierarquiza alternativas e responsabiliza o sujeito individual por suas consequências, o cuidado é um processo complexo "em desenvolvimento", no qual intervêm saberes, redes sociais, tecnologias, tarefas e corpos.

Questionando a dissociação entre a biomedicina e o dar cuidado, Kleinman (2009) caracteriza esta última como uma atividade complexa que consome energia, tempo e recursos financeiros, e que integra e é produtora de angústia, conflitos e incertezas. A divisão de trabalho entre médicos e 
"cuidadores" (assistentes sociais, terapeutas ocupacionais, membros da família, amigos etc.) relaciona-se, por um lado, com a dissociação e o privilégio da racionalidade técnica do saber biomédico e, por outro, com a atenção, o compromisso diário e a assistência.

Por sua vez, a noção de cuidado foi incorporada aos estudos que examinam os modos com que as lógicas de poder normalizam e controlam a vida das populações e participam dos processos de produção de sujeitos. É possível reconhecer diversas formas de cuidado: institucionais, vinculares e autorreferenciais (Bonet \& Gomes Tavares 2007). Através dessas práticas e desses saberes são modelados os corpos sociais e individuais, convertendo a saúde em paradigma da moral (Crawford 1994). Seguindo Foucault e colocando ênfase nas práticas autorreferenciais, as técnicas de cuidado de si mesmo, ou o autocuidado, referem-se a modos com que o poder, apoiando-se nos sujeitos individuais, delega a outros o desenvolvimento de atividades de controle e normalização (Foucault 2006). Essa delegação no campo das doenças e dos padecimentos, por sua vez, torna responsáveis os próprios sujeitos por seus resultados, ou seja, por sua saúde e suas doenças.

Embora no campo da saúde pública a noção de tecnologia esteja estreitamente associada à medicina baseada na evidência, esta noção de Foucault (1989) permitiu reconhecer e categorizar como técnicas - em termos produtivos — os diversos conjuntos de práticas e saberes que participam de redes difusas de poder, e que são suscetíveis de serem apropriados e readaptados em diferentes contextos por diferentes conjuntos sociais, além de suas condições de origem (Ayres 2000, 2004; Pinheiro \& Gomes da Silva Jr. 2010). ${ }^{1}$

Com base em Foucault e nesses desenvolvimentos, no presente trabalho, analiso o conjunto de práticas e saberes, em termos de técnicas e táticas, como uma tecnologia social categorizada como cuidado nesses contextos locais. Por sua vez, esta tecnologia com foco no cuidado dos/as usuários/as de drogas é formada por práticas e saberes heteróclitos, isto é, com diferentes genealogias e condições sociais de formação e, portanto, distintos efeitos produtivos. Por essa razão, as práticas e os saberes desta tecnologia respondem a modelos diversos de subjetividades, noções de autonomia-dependência e variadas orientações sobre o bem-estar e a saúde.

As práticas e os saberes que formam esta tecnologia voltada para a resolução de problemas associados ao consumo de drogas em condições de crise são suscetíveis de serem agrupados em três fontes principais. Algumas dessas práticas eram extensões, adaptações e redefinições daquelas disponíveis nas tradições de cuidado dessas populações (Jelin 2010). Outras foram produzidas no que concerne ao que denominei de "privatização do cuidado", 
quer dizer, com os deslocamentos e as delegações de diversas instituições estatais ou particulares (trabalho, assistência social, saúde, educação etc.) para as redes sociais locais e vínculos próximos (Escudero 2003; Epele 2010). Por último, é possível reconhecer outras práticas que produzem certa estranheza e que se referem tanto às práticas e às estratégias disponíveis no dispositivo judiciário-policial-sanitário quanto àquelas das quais estas populações são objeto há décadas.

\section{Sobre encerramentos e (maus) tratos}

À diferença de outras tecnologias, as práticas e os saberes com foco no cuidado dos jovens usuários/as de drogas - ou que ao menos são categorizados desse modo nos contextos locais - apresentam desafios particulares. Enquanto algumas delas não oferecem, em um primeiro momento, problemas diretos em sua categorização como "cuidado", outras produzem estranheza, incerteza e críticas não só em alguns residentes desses bairros, como também, e especialmente, em outros setores sociais, como, por exemplo, em certos profissionais e especialistas. Para incluir na análise esta singularidade entre as práticas e as categorias locais, é necessário considerar que o cuidado é construído social e historicamente em sociedades particulares, em relação aos domínios específicos da vida cotidiana, sendo, portanto, atravessado pelos processos econômicos, políticos, institucionais e normativos.

Para incluir esta singularidade na análise, acrescento a perspectiva que Ulloa (1995) definiu sobre as particularidades dos maus-tratos em diversos contextos sociais na história argentina das últimas décadas. Partindo do estudo da tortura durante a ditadura militar argentina (1976-1983), Ulloa desenvolveu a noção de encerramento trágico como núcleo central do que denominou o dispositivo da crueldade. Este encerramento cruel é uma situação com duas posições, sem uma terceira para apelar, só a vítima e o algoz, na qual a vítima depende do algoz para deixar de sofrer e/ou sobreviver.

Longe de limitar esta situação à ditadura, Ulloa identifica diversos encerramentos, situações sem saída, na história argentina das últimas décadas. O hospital psiquiátrico e outras instituições totais podem ser reconhecidos como a expressão paradigmática e tradicional desses encerramentos. Porém, as transformações econômicas e sociais neoliberais multiplicaram as condições de produção de tais encerramentos e suas estruturações. Eles se configuram cada vez que alguém, para deixar de sofrer, para satisfazer suas necessidades elementares, trabalhar, viver, educar-se, inclusive morrer, depende de alguém ou de algo que o maltrata, ou que não o assiste, ou 
seja, que não o reconhece como sujeito (Ulloa 1995; Altschul \& Taber 2005). A institucionalização crônica, as condições trabalhistas arbitrárias e/ou de coação, a violência crônica no bairro e/ou no âmbito doméstico, os diferentes maus-tratos existentes em medidas técnico-administrativas da burocracia estatal configuram novos encerramentos que evidenciam diversas tragédias sociais e subjetivas. Em oposição aos maus-tratos, o "bom trato" refere-se a todo tratamento e relacionamento social que inclua a singularidade subjetiva e a escuta baseada na legitimidade e no reconhecimento da demanda da pessoa que dele padece. Em oposição à crueldade, a noção de ternura é para Ulloa a base do "bom trato", como defesa e escudo protetor contra a violência social.

A transformação neoliberal que teve lugar na Argentina nas últimas décadas envolveu não só o aumento da pobreza, o desemprego e a marginalização, mas também um incremento do consumo de drogas em populações marginalizadas e a precarização (privatização, terceirização e falta de investimento) do sistema público na atenção à saúde destinada a esses conjuntos sociais (Escudero 2003; Zeballos 2003). Além disso, na década de 90, aprofundaram-se e complicaram-se as estratégias complexas e combinadas de criminalização da pobreza e do consumo de drogas, que tiveram essas populações como objeto, ao mesmo tempo em que o incremento da pobreza, o desemprego e a marginalização e a montagem do dispositivo judiciário-policial-sanitário fizeram do encerramento, da internação, da abstinência, das dificuldades no acesso ao sistema de saúde, da responsabilidade individual por seus padecimentos, da culpabilidade da família e da transformação punitiva e obrigatória da subjetividade os pilares centrais e habituais dos modos experientes e institucionais de tratar o consumo intensivo de drogas (Aureano 1999).

Embora existissem sistemas ambulatórios em determinadas regiões e uma extensão progressiva dos programas de redução de danos cada vez em mais áreas, este dispositivo priorizou a disponibilidade daquelas práticas e estratégias de cuidar e tratar em detrimento de outras possíveis (Touzé 2006). Por sua vez, tal disponibilidade promoveu, por parte dessas populações, a naturalização de sua existência e a apropriação de algumas delas em diversos tipos de situações de emergência, como a resistência, a denúncia e a rejeição de outras.

Com base nessas perspectivas, o conjunto heterogêneo de práticas e saberes, que constituem a tecnologia localmente categorizada como de cuidado de outros, inclui não apenas aquelas práticas que podem ser consideradas como adaptações e ajustes das que já pertenciam ao acervo das tradições locais de cuidado, mas também integram e modificam alguns saberes, práticas e demandas ligados ao costume, à disponibilidade - 
inclusive, em certos casos, à apropriação de alguns modos de tratar — dos quais essas populações marginalizadas foram objeto em relação ao consumo problemático de drogas no passado.

Apesar de no presente trabalho serem considerados diversos problemas ligados à saúde e à sobrevivência dos/as jovens usuários/as de drogas, o foco na análise das práticas e dos saberes relativos ao rápido emagrecimento e/ou à extrema magreza tem diferentes razões. Em primeiro lugar, no acelerado dano corporal, combinam-se e condensam-se as condições extremas de vida e o uso intensivo de drogas (Touzé 2006; Epele 2010). Em segundo lugar, a magreza extrema torna visível não só as complicadas relações entre o bem-estar e a saúde dos jovens, como também as estratégias informais e institucionais disponíveis para resolvê-las. Igualmente põe em evidência a maneira com que um problema de saúde se converte em sintoma e, em certas ocasiões, justificativa para múltiplas urgências e emergências a respeito do bem-estar e da sobrevivência desses jovens em contexto de bairro, promovendo o uso das estratégias disponíveis.

\section{Sobre a magreza extrema em épocas de crise}

Está muito magro. Você viu o Pedro, agora? Tem a pele escura e a boca queimada. Era robusto e agora não sei quanto pesa, 50 quilos? Olha que falo com ele, eu lhe digo para que fique aqui, que coma. Faço que coma, mas a comida lhe faz mal. Já deve ter algo ruim por dentro. Não sei o que fazer, não se deixa cuidar...

Pedro desaparece por dias e quando volta está cada vez pior.

Levou coisas de casa e trocou-as por "Paco", até a roupa que usa, e custa muito para eu conseguir as coisas. Não sei o que fazer! [...]

Uma vez, Pedro voltou com uma ferida, toda suja, muito infectada, até pus tinha. Perguntei-lhe... o que aconteceu? E ele não sabia...

Não queria ir ao médico e se zangava... quando lhe dizia que íamos ao hospital. Depois de tanta luta, consegui curá-lo. Demorou, a ferida ficou aberta por muito tempo (Patrícia, mãe de usuário de PB/Paco).

Quando conheci Patrícia, em novembro de 2003, a generalização do consumo de Pasta Base/Paco tinha começado a modificar a já complicada topologia corporal definida pela magreza, fome, desnutrição, gordura, fortaleza, curvas marcadas, fraqueza, resistência e fragilidade entre os jovens de setores populares. ${ }^{2}$ Enquanto a magreza extrema teve lugar principalmente nas primeiras épocas da expansão de PB/Paco no contexto da crise de 
2001-2002, na atualidade ficou mais desvanecida e/ou circunscrita àqueles que permaneceram à margem das redes sociais, seus familiares e também aos consumidores em determinados bairros ou áreas geográficas. Na época da crise, quando a pobreza e a indigência chegaram aos seus níveis mais altos, esta particular e extrema magreza já assinalava, no dizer dos próprios atores, a complexidade dessas experiências:

Não estou com fome porque fumo Paco, e fumo Paco para não estar com fome. ${ }^{3}$

— E... você deixa de comer... vai deixando. Tudo é para comprar Paco, tudo... Você não tem dinheiro para comer e, se tiver, compra Paco ou o vende para comprar. Estou o dia todo enrolando, enrolando.

- E vai à sua casa?

- Sim vou, mas, quando estou, minha mãe me enche a paciência... e terminamos aos socos, e vou embora de novo.

- O que é que você come, quando come?

- É pouco, qualquer coisa, não estou com fome...

A perda de 10, 20, 30 quilos de peso, ou até mais, em um curto período de tempo, foi considerada desde o princípio e pelos próprios atores sociais como algo mais do que simplesmente emagrecer ou perder peso. O sentimento de estranheza, não só a respeito de si mesmo, mas especificamente das próprias experiências, imagens e dos sentidos corporais, introduziu, além de mal-estares e doenças, distâncias, separações e rupturas nos processos de reconhecimento e sociabilidade. Esta estranheza também atravessava as palavras tanto dos próprios jovens quanto de seus familiares: "dá para ver minhas costelas", "tenho a cara afundada", "minhas pernas são paus", "meus olhos ficaram grandes", "estou sem força", "é um esqueleto", "está magra demais". Esse repentino emagrecimento produziu uma ruptura na história pessoal e uma homogeneidade progressiva dos corpos dos jovens que experimentavam tal processo.

O Paco lhe faz mais dano quando você chega a um estado de desnutrição, a um estado de não ter alimentos e... também porque, bom, você fuma Paco e não fica com fome. Eh, pode afetar seu coração e depois as desordens que tiver podem terminar mal, depois, isto de fumar Paco e cair na depressão você pensa, sei lá.

Além disso, outros têm cãibras estomacais se não consumirem. Você tem umas cãibras terríveis. O que já vi, mas... ficam com convulsões... (Daniel, ex-usuário de PB/Paco). 
Entre as múltiplas modificações corporais, subjetivas, vinculares e de bairros associadas ao uso intensivo de $\mathrm{PB} / \mathrm{Paco}$ nos contextos locais, a extrema magreza instalou um estado de urgência que gerou um conjunto de práticas e saberes, e se converteu em um indicador, não só pelo dano corporal visível, mas também em função da rápida transformação da imagem corporal, dos possíveis e vários perigos para a saúde e a sobrevivência desses jovens (Santis et al. 2006, 2007).

\section{Práticas, saberes e técnicas}

O repentino emagrecimento, que se transformava na magreza extrema, daqueles jovens que fumavam $\mathrm{PB} / \mathrm{Paco}$ de modo intensivo nos primeiros anos da generalização do consumo desta droga chamou a atenção por ser algo inédito. Diante desse rápido emagrecimento, essas populações foram gerando, reciclando, adotando e ajustando novas e velhas técnicas e táticas para tratar dos problemas relacionados à $\mathrm{PB} / \mathrm{Paco}$ (Santis et al. 2006, 2007).

Em um primeiro momento, o rápido emagrecimento dos/as usuários/ as foi considerado pelos residentes dos bairros pobres como um efeito exclusivo da PB/Paco. Desta maneira, os movimentos iniciais para evitar este tipo de dano, que geralmente estava associado a outros mal-estares e problemas nas já complicadas relações no bairro e nos vínculos locais, foram orientados no sentido de deter o avanço desta "nova droga". Através do traçado de novas vias de informação e de comunicação, os moradores potencializaram o vínculo social (familiar, escolar etc.) entre moradores de diferentes bairros. Em alguns casos, falavam com os "transas" (transas: indivíduos que vendem droga) para pedir a eles que não deixassem entrar essa droga nos bairros ou, no outro extremo, tentavam denunciá-los. Essas tentativas visavam, basicamente, pôr barreiras entre os jovens e a $\mathrm{PB} /$ Paco como uma estratégia de cuidado dos adolescentes e jovens desta área geográfica.

Já instalada a convivência com a PB/Paco, uma das ações em que os familiares e os vizinhos concentraram esforços para enfrentar a magreza extrema consistia em identificar e reconhecer se os jovens consumiam drogas e o tipo de consumo, especificamente, se eram "viciados" ou não. De acordo com os familiares, o uso intensivo de $\mathrm{PB} / \mathrm{Paco}$ podia ser reconhecido pelos seguintes sinais heterogêneos: "rápido emagrecimento", "más companhias", "mudanças de atitude", "ausências do lar durante dias", "agressividade", "desaparecimento de coisas nas casas", entre os principais. Porém, a maio- 
ria dos familiares manifestava que reconheciam o consumo entre os jovens quando ele já era problemático, portanto, quando era "difícil de parar" e "não se sabe o que fazer", ou quando "tem que pedir ajuda", "tomar medidas". O rápido emagrecimento era considerado um dos sinais mais evidentes de que algo andava mal. Porém, e em certas ocasiões, a percepção e o reconhecimento da perda repentina de peso passavam despercebidos, sendo vinculados a outras razões, ou então o emagrecimento era um fato que não podia ser privilegiado como problema devido a outras urgências da vida cotidiana.

— Às vezes as mães não querem ver. Infelizmente temos que ver, temos que tirar esses óculos escuros que temos nos olhos, né? E ver o que é que está acontecendo com os meninos.

- Como é isso de não querer ver?

— E que às vezes as mães, talvez, digam não, meu filho, não. Aconteceu isso comigo, que dizia não, meu filho, não. Mas não, não, não, não.

- E depois, como você percebeu?

- E depois já percebi a mudança de personalidade, todas essas coisas, que já não era a mesma pessoa que eu conhecia. Então, comecei a perceber que o que me diziam era verdade. Muitas mães não querem ver isso e algumas estão vendo que é assim, mas fazem de conta que não é, estão adormecidas, estão... não sei... não reagiram ainda. Tristeza, angústia e pena, porque as pessoas os veem ou, às vezes, batem neles, machucam-nos e você os vê aí no chão, abandonados. "E isso dói muito" (Larisa, 45 anos).

Quando e como o uso é problemático nesses bairros? O intervalo entre o início do consumo e o consumo problemático, quer dizer, as dificuldades em categorizar e medir esse processo produziram diversos saberes e práticas individuais e sociais. Esta incerteza provocava, em certas ocasiões, a procura precipitada de ajuda profissional e experiente. Não era raro que familiares considerassem como "viciado" um filho ou uma filha quando o/a encontrava com um cigarro de maconha, ou com algum amigo que sabiam ser consumidor de alguma outra substância. Outros, porém, diziam que, quando os jovens estavam fumando PB/Paco de modo intensivo, inclusive em suas próprias casas, e outros familiares ou vizinhos "avisavam" aos familiares responsáveis por eles sobre esta situação, eles/as não percebiam e só tomavam conhecimento quando era "muito tarde".

Alguns perguntavam aos/às seus/suas filhos/as ou falavam com eles/ elas. Porém, para a maioria, a palavra e a comunicação "não prestam", porque se contrapõem ao "não escutar" dos jovens. Por esta razão, algumas 
mulheres pediam a conhecidas ou a vizinhas que "revistassem" as coisas de seus filhos, que "os cheirassem", ou que perguntassem a seus amigos sobre o vício. Nas conversas, no entanto, surge o questionamento daqueles outros familiares que simplesmente "não se importam", que "os deixam aí", que "os mandam embora", porque "eles mesmos tomam drogas" ou "vendem".

À diferença de outras drogas, na maioria das descrições e das narrativas dos bairros, a $\mathrm{PB} / \mathrm{Paco}$ era localizada e entendida em termos dos cenários domésticos. De acordo com os próprios atores sociais, os jovens deixavam de comer ou pulavam refeições porque "vão dar voltas por aí" por alguns dias. Como também, quando estavam em casa, dormiam ou evitavam comer, já que isto os expunha ou os obrigava a entrar em contato, escutar ou falar com algum adulto próximo. Às vezes, em época de crise, não havia comida, sempre era a mesma coisa: ou se dependia de "buscar a marmita" para a alimentação cotidiana ou de ir comer no refeitório comunitário. Além disso, a maioria das unidades domésticas nesses bairros recebia algum tipo de alimento de um programa de assistência, que era denominado em termos locais de "mercadoria". Porém, no caso da PB/Paco, acrescentavam-se outros fluxos. Como algo inédito nas transações que envolvem drogas, os "alimentos" começaram a circular como algo direta ou indiretamente intercambiável por drogas, ou seja, em alguns casos, poucos, os jovens levavam "até a comida" de suas casas para trocá-la por drogas. Miranda relata:

Ou seja, a primeira afetada é a família e depois o vizinho. Os meninos consumidores do "Paco" não vão roubar na rua. Porque perdem a força, o dano físico é... rouba em seu território, digamos, para poder consumir. É diferente de outras drogas, talvez, a cocaína ou as pílulas, que nesses casos saem para roubar fora do seu território. Mas parece que já é feito de propósito para que o menino ou as pessoas consumidoras vivam e morram ou consumam dentro de seu lugar.

Como parte de um desencontro permanente, as mulheres e os familiares em geral (avós responsáveis, irmãos mais velhos, tios etc.) faziam surgir e potencializavam aqueles recursos domésticos já conhecidos para fazer com que seus filhos, entre muitas outras coisas, comessem: "digo-lhe que coma", "não o deixo sair", "fecho-o dentro de casa", "chamo meu irmão para lhe falar", "quando acordado, lhe dou de comer", "digo-lhe que lhe dou algo se comer", "faço-lhe a comida que gosta". A situação se complicava quando havia mais escassez, porque os jovens às vezes não queriam "marmitas" dos refeitórios ou percebiam a ida ao refeitório como algo impraticável para a "sua dignidade". 
Como uma total novidade, a alternativa foi, e só em certos bairros, que algumas mulheres, especificamente mães, se organizassem para levar comida aos "fumadouros" ou às ranchadas (locais abandonados da cidade nos quais se juntam grupos de jovens viciados para viver, proteger-se e consumir drogas), a fim de evitar que os jovens perdessem peso tão rapidamente. Além de impedir o rápido emagrecimento, "enchê-los de comida" era uma prática que, de acordo com essas mesmas mulheres e os/as usuários/as, também diminuía a "ansiedade" de ter de consumir de forma imediata. Integrando-se ao acervo de saberes locais, os alimentos doces em geral, e alguns alimentos determinados (como o doce de marmelo, as guloseimas etc.) foram sendo incluídos nas dietas como os "melhores" para esta finalidade.

Além disso, esse deslocamento para os lugares onde estavam os jovens foi se convertendo progressivamente em uma nova orientação das práticas diante da tradicional necessidade de levá-los para lugares onde pudessem ser atendidos. No entanto, devido à complexidade da vida cotidiana, principalmente no que diz respeito ao trabalho e à provisão dos recursos necessários para a subsistência, era difícil sustentar ao longo do tempo este tipo de práticas e atividades. Também o rápido emagrecimento e o dano físico eram, em geral, acompanhados de outros problemas, de mal-estares e perigos tanto para os jovens usuários/as de drogas quanto para outros. Esses problemas promoveram, por parte dos familiares, o desenvolvimento de outras práticas e técnicas na tentativa de resolvê-los.

\section{"Não tinha mais jeito"}

No momento em que o PB/Paco assumiu suas características idiossincráticas nos bairros, as redes sociais já tinham uma longa experiência a respeito das alternativas disponíveis, ou ao menos dominantes, no sistema de saúde para usuários/as de drogas. A maioria destas experiências, vinculadas à AIDS, à criminalização do consumo, à internação para reabilitação e ao tratamento compulsivo, que dominaram o cenário a partir da década de 90, convertia essas populações em objeto de diversas instituições (judiciárias, de saúde, terapêuticas, religiosas etc.), que acionavam uma combinação frequentemente imprecisa entre repressão, modificação de sujeito, procura da saúde e sobrevivência.

Diante do rápido dano apresentado pelos jovens, a internação em diversas instituições (comunidades terapêuticas, hospitais psiquiátricos, de reabilitação e até mesmo penais) emergiu e se generalizou como demanda 
e expectativa, embora, em menor medida, como prática real, devido aos múltiplos obstáculos que tinham de ser levados a cabo. Se as estratégias de institucionalização já eram criticadas por familiares e usuários/as com experiências prolongadas de consumo, quais teriam sido as condições que converteram a internação em "solução" de múltiplos problemas, inclusive daqueles que incluíam o dano corporal e da saúde dos/as jovens usuários/as de drogas?

Sim, ele se internou, porque essa manhã eu saí de casa e lhe disse [que] já não quero vê-lo assim, já não é vida. Porque eu, de qualquer forma, fiquei sozinha, estou sozinha, só com ele. E quando me separei do seu pai, ele ficou pior, aí sim que já não voltava, vivia diretamente na rua, ficava até o outro dia de manhã e quebrava tudo o que tinha na casa. E, então, nesse dia ele se sentiu muito mal, sentiu todo um ardor no estômago, ele já não tinha vida, ele foi embora e pediu... foi numa terça-feira, quando ele pediu ajuda à sua irmã, e aí ela veio e me disse: "agora vou lhe dar uma boa notícia". E eu pensei, o que será? E depois me deram a notícia, mas ele se entregou porque, como disse, “eu já não posso mais". Estava... não, se ele continuasse assim, eu ficaria louca (Juana, mãe de usuário de $\mathrm{PB} / \mathrm{Paco})$.

A construção da internação como modelo paradigmático para resolver os problemas associados direta ou indiretamente ao consumo de drogas pode ser vinculada a três diferentes processos. Em primeiro lugar, a transformação do conhecido, disponível e oferecido nos sentidos terapêuticos, por meio do costume e da naturalização, ao que é adequado, normal e necessário. Há décadas, no que se refere ao consumo de drogas, as ações das instituições estiveram claramente ligadas à relação entre abstinência/proibição de consumo e internação e, de modo mais geral, à resolução de problemas associados ao consumo de drogas e internação. Além disso, esta associação na vida cotidiana foi produzida pela modalidade policialjudiciário-sanitária dominante para os jovens pobres. Em segundo lugar, os múltiplos obstáculos (pedidos de consultas, distância geográfica, falta de dinheiro para o transporte, rejeição dos jovens a irem aos centros de saúde e hospitais, dificuldades no atendimento de usuários/as no sistema de saúde etc.) tornavam outras alternativas disponíveis praticamente não relevantes para essas populações. Em terceiro lugar, podem ser citadas a modificação dos territórios marginalizados e a produção progressiva do encerramento do bairro.

A importância do acesso e da disponibilidade de alternativas de atenção, da resolução de problemas e de terapêuticas nestes contextos mostra-se 
claramente quando alguém se vê obrigado a "chamar a polícia" para resolver conflitos domésticos e vicinais, associados direta ou indiretamente ao uso de drogas.

— Depois de dias, chegou e começou a gritar, a bater nas coisas. Cláudio, meu filho mais velho, disse que parasse, gritou-lhe, agarraram-se... aos empurrões, socos. Pato não parava, e continuava, as crianças mais novas meteram-se no meio. Pato não era ele, estava irreconhecível, todo nervoso, eu não podia fazê-lo parar. Tinha medo e chamei a polícia.

$-\mathrm{E}$ ?

— Não tinha mais jeito. Não é que tenha amizade com eles, nem que goste de chamá-los.

- E o que fizeram?

- Acalmaram-no, separaram a briga deles, conversaram com eles, não tinha outra solução... a quem podia chamar?... (Mariana, mãe de usuário de PB/ Paco).

Este "chamado à polícia" entrava claramente em conflito com os modos com que essas populações experimentavam e expressavam as relações entre polícia e adolescentes/jovens de setores populares. Os moradores não só falavam sobre a participação de alguns membros desta instituição em atividades delituosas, mas também da generalização de práticas abusivas e até letais com as quais submetem e reprimem os jovens desses bairros (Pita 2010). Embora houvesse a rejeição local e as denúncias públicas que provocavam essas estratégias, de acordo com os familiares, havia um conjunto de situações extremas de urgência e emergência nas quais se fazia necessária a intervenção da polícia: conflitos e agressões, fuga do lar, ameaças e possíveis vinganças, autoagressões e tentativas de suicídios, e também o acelerado dano corporal e os diversos problemas de saúde dos jovens.

Nossa visão crítica sobre a internação tornou-se cega em face das tentativas de capturar algo que era uma contínua referência para os moradores: no decurso das últimas décadas, a experiência de encerramento mais próxima para eles consistia no bairro. Com as modificações da mobilidade social e territorial durante as reformas neoliberais, a fragmentação territorial foi tomando forma progressivamente em um "encerramento no bairro". A partir das perspectivas e das experiências locais, esse encerramento era percebido através dos modos com que os/as jovens usuários/as de drogas ficavam sujeitos/as a determinados circuitos locais de violência, o que, por sua vez, os expunha a múltiplos riscos e perigos, de saúde e sobrevivência. 
Devido ao fato de a maioria dos residentes desses bairros pertencer à primeira, à segunda ou à terceira geração desde a migração do interior do país ou de países vizinhos para esses locais, diante dos problemas direta ou indiretamente associados às drogas, já se havia estabelecido a prática de enviar os adolescentes ou jovens àqueles lugares nos quais se estendiam as redes familiares e de conhecidos, para outros bairros, províncias e até mesmo países limítrofes. Antes da chegada da PB/Paco, quando os jovens estavam em perigo, a alternativa era tirá-los do bairro, em lugar de institucionalizá-los. Porém, com a generalização do consumo da droga durante e depois da crise de 2001-2002, esta estratégia ficou ainda mais restrita. De acordo com os próprios familiares, além da falta de recursos econômicos para deslocá-los, o dano corporal acelerado, a maior frequência de agressões no âmbito doméstico, o costume por parte dos jovens de "levar" coisas das casas para trocá-las por PB/Paco, e a urgência imposta por diversos perigos nas economias locais tornaram mais complicado "mandá-los" para outro lugar, mas impunham, simultaneamente, a urgência "de se fazer algo".

Com o acúmulo das experiências, "a internação" como forma de resolver as consequências para a saúde em função do uso intensivo da $\mathrm{PB} /$ Paco - especificamente naqueles casos de magreza extrema - foi questionada por causa dos múltiplos obstáculos de levá-la a cabo da forma premente que alguns casos requeriam. Além das críticas às condições de acesso, os próprios atores sociais questionavam a internação, apontando a maneira de usar a medicação, as regras e os maus-tratos infringidos em alguns centros de internação, a chamada "recaída", a "volta ao bairro", e a continuação dos "sintomas" que, antes, se relacionavam exclusivamente com a PB/Paco. Conjuntamente com este questionamento, começaram a ser demandados e, em alguns casos, implementados outros tipos de serviços de caráter ambulatorial, baseados na resolução de problemas não só de saúde, mas também dos bairros e dos familiares envolvidos com o consumo de drogas. "E, às vezes, a gente confia, porque eu vi meninos que saíram, que estão muito bem, gordinhos. E você vê que voltam a cair novamente. Por quê?"

Como Graciela afirma acima, a ideia de que o aumento de peso era indicador da melhora da saúde dos/as usuários/as da PB/Paco começou a se dissipar. Esta constatação acompanhou o reconhecimento por parte dos próprios atores sociais de diversos e complexos processos relacionados com o consumo da PB/Paco nessas populações: o caráter cíclico do aumento e da perda de peso; a existência de períodos de consumo intensivo e outros de uso mais ocasional; a ampla gama de ameaças e perigos para a sobrevivên- 
cia que atinge os jovens para além das drogas ou que fazem das drogas só um componente de sua justificação; as dificuldades e os limites dos saberes experientes no que concerne às dinâmicas sociais dos setores populares; a modificação permanente das práticas de consumo a partir de certa aprendizagem do uso de substâncias; e, por último a minimização, por parte dos/as mesmos/as usuários/as ou de seus familiares, dos múltiplos danos associados direta ou indiretamente ao consumo intensivo. ${ }^{4}$

\section{Palavras finais}

Centrando nosso olhar no rápido emagrecimento dos/as usuários/as da PB/Paco em épocas de crise, foi possível analisar algumas das condições de emergência de práticas, técnicas e saberes que localmente eram categorizadas como de cuidado dos jovens usuários de drogas. Entre certas práticas que formam parte desta tecnologia, encontramos: o traçado ou o fortalecimento das redes e das vias de informação e comunicação; falar com os "transas", até mesmo denunciá-los; as formas de reconhecimento da existência de consumo por parte dos jovens; falar com os jovens e fazer perguntas a eles; revistar os pertences dos filhos; desenvolver atividades a respeito da alimentação ("fazê-los comer", "levar-lhes comida", "enchê-los de comida", dar-lhes alimentos específicos etc.); enviá-los a outros bairros, ao interior ou a outros países onde haja parentes; chamar a polícia; interná-los.

Salvo algumas exceções, a maioria destas técnicas e táticas não tem um vínculo "natural" ou "óbvio" com o problema que aparentemente procura abordar, nem tampouco com a ideia de que os outros setores sociais urbanos, especializados ou leigos, tenham relação com o cuidado. Por um lado, as práticas que resistem a ser imediatamente incluídas na categoria de cuidado promovem a desnaturalização do conjunto e o questionamento sobre o que se entende por cuidado nesses contextos sociais, por outro lado transformam o modo de se intervir nessas populações. Além disso, o caráter heterogêneo dos elementos desta tecnologia converte-se em um indicador de que tais práticas têm diferentes genealogias, ou seja, procedem de distintos âmbitos da experiência cotidiana, das tradições de cuidado locais, das práticas judiciáriopoliciais de que foram objeto essas populações, das estratégias das instituições de saúde ou das organizações religiosas, entre as principais.

Algumas delas (como enviar os jovens para o interior onde vivem familiares, falar, encerrar etc.) já pertenciam ao conjunto de práticas produzidas há alguns anos para resolver problemas com os adolescentes e os jovens desses bairros. Outras, porém (interrogar, revistar, internar etc.), guardam 
similitudes com as práticas, os saberes e os modos de tratar os/as usuários/ as adotados por agentes e profissionais de diversas instituições que têm participado do dispositivo judiciário-policial-sanitário durante as últimas décadas. Finalmente, outras (enchê-los de comida, falar com os "transas" etc.) são consideradas pelos próprios atores sociais como práticas e saberes desenvolvidos com o fim de enfrentar os novos problemas referentes aos jovens consumidores da PB/Paco em contexto de extrema pobreza e marginalização. Além disso, estas técnicas e táticas são alteradas no tempo: algumas são abandonadas, outras modificadas e ainda outras submetidas a contínuas revisões, críticas e questionamentos para capturar o grau de dano, os maus-tratos ou a sua falta de eficácia.

No entanto, algumas delas (especificamente chamar a polícia, revistar e internar), embora tenham sido questionadas há décadas atrás, foram realizadas ou ao menos demandadas não só por serem as dominantes e/ou as únicas disponíveis, mas também pela normalização da relação entre encerramento e efeito terapêutico. Levando em conta esses processos, podemos falar, seguindo Ulloa, de encerramentos trágicos, ou seja, a dependência para aliviar o sofrimento, a luta pela saúde e a garantia da sobrevivência em face daqueles que infringem maus-tratos e não os reconhecem como sujeitos.

Assim, esta tecnologia orientada, ou ao menos categorizada, como de cuidado de outros, impõe que se estabeleça um questionamento a respeito desses outros: os/as jovens usuários/as de drogas das populações pobres e marginalizadas. O consumo de drogas é uma prática autorreferente, ou seja, é levada a cabo pelo sujeito que tem o domínio do próprio corpo, e envolve graus variáveis de prazer e dano, os quais, por sua vez, são socialmente punidos e criminalizados. É necessário considerar as particularidades relacionadas ao consumo de drogas que fazem do cuidado de outros uma atividade complexa e específica.

O cuidar de outros, aquele que "não se sabe como cuidar" e/ou está voltado para os que "não se deixam cuidar", segundo afirmação de familiares de usuários e de vizinhos, promoveu a multiplicação de técnicas e de táticas e deu forma às suas características. Considerando as complexas e heterogêneas genealogias de tais práticas, técnicas e saberes, é possível reconhecer diferentes modelos de subjetividade e cidadania. As tradições locais de cuidado de outros mostraram-se insuficientes e, em certas ocasiões, inadequadas para enfrentar os novos problemas. Em geral, os desafios confluem em "fazer com que o outro" faça ou deixe de fazer algo, perceba e aja em relação ao perigo e à dor, deixe que os outros o atendam ou curem em relação aos problemas de saúde e à sobrevivência, e muito frequentemente, numa temporalidade marcada pela urgência e pela emergência. 
As estratégias utilizadas durante as últimas décadas têm feito de distintos modos de intervenção - em certos casos, sobre diversas formas de maus-tratos (culpabilidade, encerramentos, castigos punitivos etc.) a base das práticas e das ações consideradas terapêuticas. O costume, a normalização e a reapropriação de algumas dessas práticas e técnicas por parte das populações atingidas abrangem os modos e os modelos com que os/as usuários/as de drogas como sujeitos/objetos são abordados e tratados, e indicam as maneiras com que os macroprocessos políticos, econômicos e institucionais se traduzem em microdinâmicas sociais. Por sua vez, em função da experiência acumulada e das tentativas sem êxito, foram surgindo novas práticas com diferentes formas de aproximação: novos olhares dirigidos aos outros, mudanças nesses indivíduos e nos sujeitos que procuram cuidar de outros.

Finalmente, esta análise sobre o cuidado explica os modos como os processos de marginalização, criminalização, institucionalização e punições sociais participam da produção da tecnologia categorizada como orientada para o cuidado de outros. Esta análise pôs em evidência as múltiplas consequências que ocorrem a médio e longo prazos, produtoras das maneiras de "tratar" essas populações. Especificamente, abre a possibilidade de haver um deslocamento da forte energia despendida na preocupação, na ocupação, na impotência e no sofrimento, reorientada à produção de novos e múltiplos canais, práticas e saberes institucionais e informais, fazendo com que o "bom trato" gere novos laços sociais e subjetividades.

Recebido em 07 de maio de 2012

Aprovado em 20 de setembro de 2012

María Epele é pesquisadora do CONICET, professora da Universidad Nacional de Buenos Aires (UBA) e da FLACSO. E-mail: <mariaepele33@gmail.com> 


\section{Notas}

* A argumentação deste trabalho se baseou nos resultados da pesquisa etnográfica feita em três bairros e favelas da "Gran Buenos Aires", com usuários/as de drogas, familiares, vizinhos e profissionais (2001-2007). O processo de documentação e a análise dos dados documentados durante o trabalho de campo foram ajustados às normas do método etnográfico. As técnicas de trabalho de campo são entrevistas semiestruturadas e a observação-participante. Foram realizadas 60 entrevistas entre usuários/as de drogas (34 com homens e 26 com mulheres). As idades variam entre 18 e 55 anos, sendo a idade média 24 anos. Com aproximadamente 15 deles/as, o relacionamento continuou durante todo o período de trabalho de campo. Também foram entrevistados 13 ex-usuários/as de drogas, 20 familiares, cinco líderes locais e 10 profissionais da saúde (médicos e psicólogos). As conversas informais com a maioria deles e com outros usuários/as de drogas e residentes em geral foram documentadas em anotações de campo. A pesquisa se ajustou às normas éticas dos estudos sobre esta problemática, especificamente com a observância do protocolo de Helsinki, o consentimento informado dos participantes, a confidencialidade dos mesmos e dos lugares onde ela foi realizada. Os nomes utilizados neste trabalho foram, portanto, modificados.

${ }^{1}$ A noção de tecnologia de Foucault, como um conjunto de saberes e técnicas que participam de redes difusas de poder, teve valor heurístico para dar conta de protestos, manifestações, denúncias, ou seja, para além dos contextos em que foram produzidos (Foucault 1989; Pita 2010; Manzano \& Triuguff 2010).

${ }^{2}$ A noção de segurança alimentar refere-se ao "direito de todas as pessoas terem uma alimentação cultural e nutricionalmente adequada e suficiente" (Aguirre 2004:1). A discussão histórica e crítica desta noção a partir da perspectiva antropológica foi realizada por Aguirre (2004).

${ }^{3}$ Estas expressões, que assinalam a complexidade da combinação entre a pobreza, o consumo de drogas e o dano corporal, também foram documentadas em outros estudos sobre o tema (vide Touzé 2006).

${ }^{4}$ Por exemplo, na etapa inicial da PB/Paco reproduziu-se uma série de práticas que foram rapidamente abandonadas: as reprimendas aos transas, as denúncias a policiais/juízes, e também passeatas, denúncias e demandas públicas nos meios de comunicação tampouco tiveram os resultados esperados. Pelo contrário, em alguns casos foram contraproducentes. A maioria, porém, já conhecendo na própria carne as características da lógica da violência, evitou essas práticas devido aos "efeitos secundários" da exposição (ameaças, mudanças para outros bairros, desconfiança e tensões internas aos bairros etc.). 


\section{Referências bibliográficas}

AGUIRRE, Patricia. 2004. Ricos flacos, gordos pobres. Buenos Aires: Capital Intelectual.

ALTSCHUL, Carlos \& TABER, Beatriz. 2005. Pensando Ulloa. Buenos Aires: Libros del Zorzal.

AUREANO, Guillermo. 1999. La construction politique du toxicomane dans l'Argentine post-autoritaire. Un cas de citoyenneté à basse intensité. Montreal: Les Presses de l'Université de Montréal.

AYRES, José Ricardo de Carvalho Mesquita. 2000. "Cuidado. Tecnologia ou sabedoria prática". Interface, Comunicação, Saúde, Educação, 6:117-120. - 2004. "Cuidado e reconstrução das práticas de saúde". Interface, Comunicação, Saúde, Educação, 8(14):73-92. BONET, Octavio \& TAVARES, Fátima Gomes. 2007. "O cuidado como metáfora nas redes das práticas terapêuticas". In: R. Pinheiro \& R. Araujo de Matos (orgs.), Razões públicas para a integralidade em saúde: o cuidado como valor. Rio de Janeiro: Editorial do Centro de Estudos e Pesquisa em Saúde Colectiva. pp. 262-276.

CRAWFORD, Robert. 1994. "Boundaries on the self and the unhealthy other: reflections on health, culture and AIDS". Social Science and Medicine, 38(10):1347-65.

EPELE, María. 2010. Sujetar por la herida. Una etnografía sobre drogas, pobreza y salud. Buenos Aires: Paidós. . 2011. "New toxics, new poverty. A social understanding of freebase cocaine/ Paco in Argentina". Substance, Use \& Misuse, 46(12):1468-1476.

ESCUDERO, José. 2003. "The health crisis in Argentina". International Journal of Health Services, 33(1):129-136.
FOUCAULT, Michel. 1989. Vigilary castigar. El nacimiento de la prisión. Buenos Aires: S. XXI.

- 2006. La hermenéutica del sujeto. Buenos Aires: Fondo de Cultura Económica.

JELIN, Elizabeth. 2010. Pan y afectos. La transformación de las familias. Buenos Aires: Fondo de Cultura Económica. KLEINMAN, Arthur. 2009. "Caregiving. The odyssey of becoming more human". The Lancet, 373:292-293.

- \& HANNA, Briget. 2008. "Catastrophe, caregiving and today's biomedicine". Biosocieties, 3:287-301.

HELD, Virginia. 2006. The ethic of care: personal, political and global. New York: Oxford University Press.

MANZANO, Virginia \& TRIUGUFF, Matías. 2010. " Las ocupaciones de espacios públicos y privados lideradas por organizaciones de desocupados y asambleas: procesos, tramas y significaciones". In: A. Massetti; E. Villanueva \& M. Gómez (orgs.), Movilizaciones, protestas e identidades colectivas en la Argentina del bicentenario. Buenos Aires: Nueva Trilce. 173-196.

MIGUEZ, Hugo. 2007. "El uso de $P B /$ Paco y la segunda exclusión". Acta Psiquiatrica y Psicológica de America Latina, 53(1):18-22.

MOL, Annemarie. 2008. The logic of care. Health and the problem of patient choice. London: Routledge.

ORTALE, Susana. 2005. "La comida de los hogares: estrategias e inseguridad alimentaria". In: S. Ortale \& A. Eguia (orgs.), Los significados de la pobreza. Buenos Aires: Ed. Biblos. pp. 87-98. PINHEIRO, Roseni \& SILVA JR., Aluisio Gomes da (orgs.). 2010. Por uma sociedade cuidadora. Rio de Janeiro: Cepesc-IMS/UERJ-Abrasco. 
PITA, María. 2010. "Formas populares de protesta. Violencia policial y familiares del gatillo fácil". In: A. Massetti; E. Villanueva \& M. Gómez (orgs.), Movilizaciones, protestas e identidades colectivas en la Argentina del bicentenario. Buenos Aires: Nueva Trilce. pp. 323-342.

SANTIS, Rodrigo; HIDALGO, Carmen; HAYDEN, Virginia \& ANSELMO, Esteban. 2007. "Consumo de sustancias y conductas de riesgo en consumidores de pasta base de cocaína y clorhidrato de cocaína no consultantes a servicios de rehabilitación". Rev. Med. Chile, 135:45-53.

SANTIS, Rodrigo et al. 2006. "Patrones de consumo de sustancias de una muestra no consultante de consumidores de pasta base de cocaína". Revista Chilena de Neuro-psiquiatría, 44(1):15-22.

SEDRONAR / Secretaría de Prevención y Lucha contra el Narcotráfico. 2007. Aspectos cualitativos del consumo de PBC/paco. Buenos Aires: Sedronar.

SVAMPA, Maristella. 2005. La sociedad excluyente. La Argentina bajo el signo del neoliberalismo. Buenos Aires: Taurus.

TOUZÉ, Graciela (ed.). 2006. Saberes y prácticas sobre drogas. El caso de la pasta base de cocaína. Buenos Aires: Intercambios Asociación Civil.

TRONTO, Joan. 1994. Moral boundaries. A political argument for an ethic of care. London: Routledge.

ULLOA, Fernando. 1995. La novela clínica psicoanalítica. Buenos Aires: Paidós.

ZEBALlOS, José. 2003. Efectos sociosanitarios de la crisis del 2001-2003. Disponível em: www.ops.org.ar/publicaciones. 


\section{Resumo}

A coordenação temporária entre a rápida extensão do consumo de Pasta Base/Paco (PB/Paco) e a extrema crise econômicopolítica (2001-2002) na Argentina promoveu profundas modificações nas redes sociais, nas características corporais e nos problemas de saúde das populações marginalizadas. Partindo dos resultados da pesquisa etnográfica em três bairros e favelas da área metropolitana de Buenos Aires, analiso neste trabalho as características e as tensões das práticas e dos saberes localmente categorizados como "cuidado de outros", sendo estes outros, usuários/as de drogas em geral e de PB/Paco. Através da análise dos desenvolvimentos em ciências sociais e antropologia sobre a temática do cuidado nas últimas décadas, neste artigo examino os modos com que tais práticas e saberes expressam os conflitos e os encerramentos gerados pelas tensões entre as tradições locais de cuidado e os modos institucionais de abordar o uso problemático de drogas e de tratar seus/suas usuários/as.

Palavras-chave Cuidado, Técnicas, Marginalização, Uso de drogas.

\section{Abstract}

The temporary relationship between the rapid spread of freebase cocaine/paco (PB/paco) and the extreme political-economic crisis (2001-2002) in Argentina engendered deep changes to the social networks, bodily characteristics and health issues of marginalized populations. The present article is based on ethnographic research that I carried out in three neighborhoods (villas) located in the Metropolitan Area of Buenos Aires. Here, I analyze the characteristics of practices and knowledge locally categorized as "care towards others", specifically drug users and, most specifically, $\mathrm{PB} /$ paco users. Taking as my point of departure the problematization of care in the social sciences and anthropology during the last decades, this paper examines the ways in which these practices and knowledge express conflicts and entrapments generated by the tensions between local traditions of care, on the one hand, and institutional strategies orientated to intensive drug use and modes of treating drug users, on the other.

Key words Paco, Argentina, Marginalized Populations, Care. 